\title{
John G. Hocking
}

\section{Som Naimpally}

John G. Hocking (Gib), emeritus professor of mathematics at Michigan State University, passed away on March 23, 2011, at the age of ninety. He left behind Judy, his wife of sixty-seven years, four children, five grandchildren, and four great-grandchildren. Gib was a versatile individual with a wide variety of interests and hobbies. Besides his lifelong passion for mathematics, he was adept at many activities, including fencing, racing cars, tennis, sailing, and carpentry. During WWII he worked in aerial reconnaissance and flew planes along the India-Burma border. As a person he was always upbeat and enlivened any gathering with interesting anecdotes and his "positive-definite" attitude.

Gib received his Ph.D. from the University of Michigan in 1953 under Gail S. Young. His dissertation title was "On Approximations to Monotone Mappings on Two-Dimensional Manifolds" [1]. He joined MSU in 1951 and remained there until his retirement in 1987. During 1962-63, Gib went to Tübingen on sabbatical as a Fulbright scholar. He lectured and wrote a paper [12] in German. He also lectured in London (1970-71), Oxford (1971), Dublin (1977-78), and Shanghai (1981).

I first encountered Gib in the fall of 1961 when he gave a colloquium talk at MSU. I had just arrived from India as a graduate student, desiring to work in fluid mechanics, with no knowledge of abstract mathematics. Yet Gib's talk completely engaged not only me but the entire audience as well. I immediately decided to work with him. In the winter quarter of 1962 I took Gib's introductory topology course based on the well-known book Topology, which he wrote with his teacher, Gail Young [2]. His teaching style was superb, and within just two weeks he had taught us the latest research he had done on "invertible spaces" with Pat Doyle [3], [4]). It was about the simplest characterization of an $n$-sphere as an invertible manifold. They continued their investigations on invertible spaces in several papers, some with graduate students [5], [6], [7], [8], [9], [10], [11].

Later, when he became my thesis advisor, the first thing he told me was, "The office hours posted on the door don't apply to you. You are welcome to meet me at any time." Whenever I gave him my work, he gave it his immediate attention, setting aside his own, and returned the material with suggestions. Several years after I graduated, Gib worked with me and my under-

Som Naimpally is Lakehead University Professor Emeritus of Mathematics. His email address is somna impa17y@yahoo. ca. DOI: http://dx.doi.org/10.1090/noti960 graduate student, Phil Cameron, on using the concept of "near and far" of Frederick Riesz in teaching calculus [13]. In 2009, Gib worked with me again on writing a booklet on the same topic [14]. Even at the age of eighty-eight he was as prompt in his replies (via emails) as he was in his younger days. His enthusiasm for mathematics and for new research was still just as vivid. On March 22, just a day before he passed away, my wife, Sudha, and I visited Gib and Judy, who were taken care of by their daughters, Megan and Wendell, in Michigan. In spite of being physically weak, his lively spirit shone through, which is how he will always be remembered.

\section{References}

[1] JoHN G. HockING, Approximations to monotone mappings on noncompact two dimensional manifolds, Duke Math. J. 21 (1954), 639-651.

[2] John G. Hocking and Gail S. Young, Topology, Addison-Wesley Publishing Co., Inc., Reading, MALondon, 1961. Reprinted, Dover Publications, Inc., New York, 1988.

[3] P. H. DOYLE and J. G. Hocking, A characterization of Euclidean $n$-space, Michigan Math. J. 7 (1960), 199-200.

[4] _ Invertible spaces, Amer. Math. Monthly 68 (1961), 959-965.

[5] _ Continuously invertible spaces, Pacific J. Math. 12 (1962), 499-503.

[6] __ Dimensional invertibility, Pacific J. Math. 12 (1962), 1235-1240.

[7] P. H. DOYLE, J. G. Hocking, and R. P. Osborne, Local invertibility, Fund. Math. 54 (1964), 15-25.

[8] P. H. DOYLE and J. G. HockING, Another definition of invertibility, Publ. Math. Debrecen 16 (1969), 91-92.

[9] M. D. GUAY, J. G. HockING, and H. V. KRONK, Local near-homogeneity, Amer. Math. Monthly 70 (1963), 827-833.

[10] J. G. Hocking, Inversion about a set, Arch. Math. (Basel) 15 (1964), 343-350.

[11] P. H. DOYLE and J. G. HockING, Continuously invertible spaces, Pacific J. Math. 12 (1962), 499-503.

[12] J. G. HockING, Schwache lokale Invertierbarkeit (German), Arch. Math. 15 (1964), 46-49.

[13] P. CAMERON, J. G. Hocking, and S. A. NAIMPAlly, Nearness-A better approach to continuity and limits, Amer. Math. Monthly 81 (1974), 739-745.

[14] JOHN G. HockING and SOMASHEKHAR A. NAIMPALLY, Nearness-A better approach to continuity and limits, Allahabad Mathematical Society Lecture Note Series, 3, Allahabad Math. Soc., Allahabad, 2009. 